\title{
Endovascular therapy of acute ischemic stroke: report of the Standards of Practice Committee of the Society of Neurolnterventional Surgery
}

\author{
K A Blackham, ${ }^{1}$ P M Meyers, ${ }^{2}$ T A Abruzzo, ${ }^{3}$ F C Alberquerque, ${ }^{4} \mathrm{D}$ Fiorella, ${ }^{5}$ \\ J Fraser, ${ }^{6}$ D Frei, ${ }^{7}$ C D Gandhi, ${ }^{8}$ D V Heck, ${ }^{9}$ J A Hirsch, ${ }^{10}$ D P Hsu, ${ }^{1}$ M Jayaraman, ${ }^{11}$ \\ S Narayanan, ${ }^{12} \mathrm{C}$ Prestigiacomo, ${ }^{13} \mathrm{~J}$ L Sunshine, ${ }^{1}$ on behalf of the Society for \\ Neurolnterventional Surgery
}

For numbered affiliations see end of article.

\section{Correspondence to}

Dr K A Blackham, Department of Radiology, University Hospitals of Cleveland, Case Western Reserve University, 11100 Euclid Ave, Cleveland, OH 44106, USA; kristine. blackham@uhhospitals.org

Accepted 20 December 2011 Published Online First 24 January 2012

\begin{abstract}
Objective To summarize and classify the evidence for the use of endovascular techniques in the treatment of patients with acute ischemic stroke.

Methods Recommendations previously published by the American Heart Association (AHA) (Guidelines for the early management of adults with ischemic stroke (Circulation 2007) and Scientific statement indications for the performance of intracranial endovascular neurointerventional procedures (Circulation 2009)) were vetted and used as a foundation for the current process. Building on this foundation, a critical review of the literature was performed to evaluate evidence supporting the endovascular treatment of acute ischemic stroke. The assessment was based on guidelines for evidence based medicine proposed by the Stroke Council of the AHA and the University of Oxford, Centre for Evidence Based Medicine (CEBM). Procedural safety, technical efficacy and impact on patient outcomes were specifically examined.
\end{abstract}

\section{RECOMMENDATIONS}

1. The availability of intra-arterial therapy should generally not preclude the intravenous administration of recombinant tissue plasminogen activator (rt-PA) in otherwise eligible patients (American Heart Association (AHA) Class I, Level of Evidence A, Centre for Evidence Based Medicine (CEBM) level $1 \mathrm{~b}$, grade $\mathrm{A}-\mathrm{B}) .{ }^{*}$

2. Treatment requires the patient to be at an experienced stroke center with rapid access to cerebral angiography and qualified interventionalists (AHA Class I, Level of Evidence C, CEBM level $2 \mathrm{C}$, grade $\mathrm{C})$. $^{*}$

3. Intra-arterial chemical thrombolysis is an option for the treatment of selected patients with major stroke of $<6 \mathrm{~h}$ duration due to an occlusion of the middle cerebral artery and who are not otherwise candidates for intravenous rt-PA (AHA Class I, Level of Evidence B, CEBM level $2 b$, grade $B)$.

4. Intra-arterial chemical thrombolysis is reasonable for patients who have contraindications to the use of intravenous thrombolysis, such as recent surgery (AHA Class IIa, Level of Evidence C, CEBM level 4 , grade C).*

5. Combination intravenous/intra-arterial therapy is reasonable in selected patients who present with major stroke of $<4.5 \mathrm{~h}$ duration (AHA Class IIa, Level of Evidence B, CEBM level 2a, grade $\mathrm{B})$.

6. Intra-arterial thrombus removal with the Penumbra aspiration system or Concentric MERCI clot retrieval device is reasonable in selected patients with major stroke where care has been initiated at $<8 \mathrm{~h}$ duration although data regarding improvement of clinical outcomes is unclear (AHA Class IIa, Level of Evidence $\mathrm{B}, \mathrm{CEBM}$ level $2 \mathrm{a}$, grade $\mathrm{B}$ ).

7. The usefulness of other endovascular devices is not yet established, but they may be beneficial and may be considered (AHA Class IIb, Level of Evidence C, CEBM level 4, grade C.)*

8. The usefulness of endovascular treatment in the posterior circulation is not yet established, but it may be beneficial and may be considered, even beyond the 6-8h time window typical for anterior circulation stroke (AHA Class IIB, Level of Evidence C).

*As already defined by the AHA guidelines for the early management of adults with ischemic stroke (Circulation 2007) and AHA statement regarding indications for the performance of intracranial endovascular neurointerventional procedures (Circulation 2009). ${ }^{12}$

\section{INTRODUCTION}

Stroke is the third leading cause of death in the USA, Canada, Europe and Japan. According to the American Heart Association (AHA) and the American Stroke Association, there are now 795000 new strokes that occur each year, resulting in 200000 deaths, or 1 of every 16 deaths, per year in the USA alone. $^{3}$ Ischemic stroke accounts for more than $80 \%$ of the total while hemorrhagic stroke accounts for the remainder. Stroke is the leading cause of adult disability in North America ${ }^{4}$ and the primary cause for inpatient Medicare reimbursement for long term adult care. ${ }^{5} 6$ The National Institutes of Health estimates that stroke costs now exceed $\$ 62$ billion in US healthcare dollars per year. ${ }^{7}$ There are varying estimates as to potential numbers of ischemic stroke patients that might benefit from endovascular therapy but many expect an expansion of the number of patients treated with these techniques. ${ }^{8} 9$

The purpose of this document is to define the existing scientific basis for endovascular acute 
ischemic stroke (AIS) treatment. The discussion of what constitutes adequate training and experience in endovascular surgical neuroradiology, both cognitive and technical, has been published elsewhere. ${ }^{10}$ In addition, national professional organizations have published performance and training standards for cervicocerebral angiography. ${ }^{11} 12$ Quality improvement guidelines for adult diagnostic cervicocerebral angiography have also been formally adopted by professional specialty societies. ${ }^{13}$ Adherence to these standards and guidelines is a prerequisite and fundamental for any interventional stroke treatment procedure.

Guidelines for performance of endovascular ischemic stroke therapy represent a multidisciplinary effort to reduce death and disability from this condition. These guidelines intend to encompass the training and experience of all physicians involved in the care of patients with cervicocerebral vascular disease regardless of medical specialty. In developing the present recommendations, the writing group conducted a systematic review of English language literature published between January 1998 and January 2011 to evaluate the evidence supporting the endovascular treatment of AIS, as well as incorporating already existing guidelines published by the AHA. ${ }^{12}$ The writing group has applied the rules of evidence ${ }^{14}$ and formulation of strength of recommendations used by other AHA guideline panels, and by the University of Oxford, Center for Evidence Based Medicine (CEBM) ${ }^{15-17}$ Procedural safety, technical efficacy and impact on patient outcomes were specifically examined.

Endovascular therapy for patients with AIS is an area of intense investigation and brisk technological development. This, in combination with the fact that the outcome of AIS may depend on numerous variables, such as thrombus type, location and clot burden, individual patient parameters like age, collateral circulation and underlying comorbidities, as well as time to treatment, unfortunately restricts the availability of standardized outcomes research. Intra-arterial (IA) thrombolysis has been studied in two randomized trials ${ }^{18} 19$ and numerous case series and is endorsed by national organizations as an acceptable alternative stroke therapy, in selected patients. In the past decade, two devices received Food and Drug Administration (FDA) approval for safety and efficacy in endovascular thrombus removal. ${ }^{20} 21$ Several other devices, drugs and other reperfusion strategies are used off-label or are in development with the goal of obtaining the most rapid and complete recanalization possible, while minimizing vascular damage and hemorrhagic complications.

\section{INTRAVENOUS THROMBOLYSIS}

The availability of intra-arterial therapy should not preclude the intravenous administration of recombinant tissue plasminogen activator (rt-PA) in otherwise eligible patients (AHA Class I, Level of Evidence A, CEBM level 16, grade $A-B)$.

At present, the only therapy demonstrated to improve clinical outcomes from AIS in randomized controlled clinical trials is thrombolysis of the clot responsible for the ischemic event. ${ }^{22-25}$ Specifically, since 1996, intravenous (IV) thrombolysis with recombinant tissue plasminogen activator (rt-PA) is FDA approved for the treatment of ischemic stroke to patients without evidence of hemorrhage seen on initial non-contrast head CT, if treatment is initiated within $3 \mathrm{~h}$ of a clearly defined symptom onset. A 2009 scientific advisory from the AHA/ American Stroke Association ${ }^{26}$ recommended extension of the time window for treatment with IV rt-PA to $4.5 \mathrm{~h}$, largely based on the prospective, randomized, placebo controlled European Co-operative Acute Stroke Study III (ECASS III) trial. ${ }^{23} \mathrm{rt}-\mathrm{PA}$ is administered intravenously at a dose of $0.9 \mathrm{mg} / \mathrm{kg}$ (maximum of $90 \mathrm{mg}$ ) with $10 \%$ of the total dose given as a bolus with the remainder infused over $60 \mathrm{~min}^{26} 27$ This dosage has been shown to be safe and effective in routine clinical use, with results comparable with pooled, randomized, controlled trial data in the Safe Implementation of Thrombolysis in StrokeMonitoring Study (SITS-MOST), a large observational registry. ${ }^{28}$ As noted below in the section on combination therapy (IV plus IA rt-PA), several trials and case series have shown that patients with a large clot burden are not likely to achieve recanalization with IV rt-PA. A 2011 retrospective review of 138 patient treated with IV rt-PA demonstrated that of the 76 patients who did not achieve recanalization, the majority had clot lengths which exceeded $8 \mathrm{~mm}$. Clot length was determined via automated measurements of vascular hyperdensity on thin section pretreatment CT scans. The remaining patients who did achieve recanalization had clot lengths of $<8 \mathrm{~mm}^{29}$

\section{ENDOVASCULAR TREATMENT}

Treatment requires the patient to be at an experienced stroke center with rapid access to cerebral angiography and qualified interventionalists (AHA Class I, Level of Evidence C, CEBM level 2c, grade C).

Endovascular treatment of stroke requires the infrastructure to support the rapid assessment, stabilization and transport of patients with AIS, along with documented procedures for communication with the receiving hospital emergency room and stroke team. Evaluation of the patient before and after the procedure requires a multidisciplinary team approach not only for discussion of endovascular treatment options, particularly on full evaluation of the underlying vascular disease, but also for evaluation and treatment of the attendant complications. Nursing and technological staff should have training in endovascular procedures and should be available on a continuous basis with a $60 \mathrm{~min}$ response time to the hospital. There should be documentation and evaluation of procedural indications, outcomes and complications with the support of a quality assurance program. This brief description of an experienced stroke center is subsumed within the more detailed evidence based guidelines describing the concept of a Comprehensive Stroke Center (CSC), defined by the Brain Attack Coalition in 2005 as a facility or system that is able to "diagnose and treat stroke patients who require a high intensity of medical and surgical care, specialized tests or interventional therapies". ${ }^{30}$ The CSC is the highest level of stroke care within the auspices of larger 'stroke systems of care', as advocated by the American Stroke Association. ${ }^{31}$

A Center for Disease Control and Prevention evaluation of data from the 2005-2007 Paul Coverdell National Acute Stroke Registry recommends that coordinated stroke programs and surveillance of performance measures are needed in order to improve adherence to measures that improve the stroke quality of care. ${ }^{32}$ The 'Get With The Guidelines' stroke program of the AHA is a national stroke quality improvement program developed to reduce disparities in acute stroke care. Voluntary cooperation with this program is associated with substantial and sustained improvement in hospital based acute stroke care regardless of hospital size, geography and teaching status. ${ }^{33}$ Since the original publication of Primary Stroke Center recommendations in 2000, there have been over 800 facilities certified by the Joint Commission and improved outcomes have been validated by several studies evaluating the stroke systems of care. $^{34}$ 


\section{INTRA-ARTERIAL THROMBOLYSIS}

Intra-arterial thrombolysis is indicated for the treatment of selected patients with major stroke of $<6 \mathrm{~h}$ duration due to an occlusion of the middle cerebral artery (AHA Class I, Level of Evidence B, CEBM level $2 b$, grade $B$ ).

Intra-arterial thrombolysis is reasonable for patients who have contraindications to the use of intravenous thrombolysis, such as recent surgery (AHA Class IIa, Level of Evidence C, CEBM level 4, grade C).

IA thrombolysis provides a supplement or alternative to IV thrombolysis in carefully selected patients with AIS. Delivery of fibrinolytic agents directly into the thrombus permits administration of a smaller dose of the agent, which theoretically decreases the risk of cerebral and systemic hemorrhagic complications from systemic effects. ${ }^{35}$ This concept led to studies that were designed to explore an extension of the treatment window beyond the relatively short therapeutic window for IV rt-PA. Two randomized, multicenter, controlled trials of IA thrombolysis in acute middle cerebral artery stroke have been completed-the Prolyse in Acute Cerebral Thromboembolism Trial I (PROACT-I) ${ }^{18}$ and PROACT-II. ${ }^{19}$ Recanalization efficacy and safety of IA recombinant pro-urokinase (r-proUK) for middle cerebral artery occlusion of $6 \mathrm{~h}$ duration was demonstrated in the PROACT-I trial. PROACT-II demonstrated a $15 \%$ absolute increase in good outcome. The results of PROACT-II, although encouraging, were insufficient to secure FDA approval of r-proUK for an acute stroke indication. For this reason, IA thrombolysis using any thrombolytic agent still represents an 'off-label' use of r-proUK or rt-PA. The clinical benefits observed in the PROACT II study were confirmed in a recent meta-analysis of five randomized IA therapy trials, which included PROACT I, and the prematurely halted Japanese Middle Cerebral Artery Embolism Local Fibrinolytic Intervention Trial (MELT) trial, which also found higher rates of good and excellent clinical outcomes in patients undergoing IA therapy. ${ }^{36}$ In addition, several studies have suggested that successful recanalization correlates with improved clinical outcomes in patients with AIS secondary to large vessel occlusion. ${ }^{37} 38$ Retrospective studies have shown that IA thrombolysis within $3 \mathrm{~h}$ is possible at experienced stroke centers and does not significantly increase risk in patients who have contraindications to IV thrombolysis, such as recent surgery. ${ }^{39-41}$ The AHA/American Stroke Association Council endorses IA thrombolysis as an acceptable stroke therapy in major stroke of $<6 \mathrm{~h}$ duration due to an occlusion of the middle cerebral artery in patients ineligible for IV thrombolysis. ${ }^{1} 2$

\section{COMBINATION TREATMENT}

Combination intravenous/intra-arterial therapy is reasonable in selected patients who present with major stroke of $<4.5 \mathrm{~h}$ duration (AHA Class IIa, Level of Evidence B, CEBM level $2 a$, grade B).

IV thrombolysis has the advantage of ease and efficiency of administration while IA thrombolysis has the potential for superior recanalization, particularly in proximal occlusions. Combining the two techniques was studied in the 1999 Emergency Management of Stroke (EMS) Bridging Trial ${ }^{42}$ and the Interventional Management of Stroke (IMS) studies I and II, published in 2004 and 2007, respectively. ${ }^{43} 44$ The results of IMS II confirmed the safety and increased recanalization rates initially observed in the EMS bridging trial. In IMS I, patients were administered two-thirds dose IV rt-PA followed by IA rt-PA administration. This approach yielded favorable outcomes in $33 \%$ of subjects which was significantly greater than the outcome of the historical control group (the placebo arm from the National Institute of Neurological Disorders and Stroke (NINDS) trial) but not significantly different from the historical purely IV thrombolysis group. Both IMS I and II found that IV therapy alone rarely achieved recanalization of large vessel occlusion. Several case series have supported these findings. ${ }^{4-47}$ Currently, a larger phase III, randomized, controlled IMS III trial is comparing the combined IV/IA approach to standard IV rt-PA therapy alone. Due to the intervening development and FDA clearance of new devices, IA treatment in IMS III allows the use of the EKOS ultrasound microcatheter (which was used to augment thrombus fragmentation in IMS II), the Penumbra thrombo-aspiration system as well as the Concentric MERCI clot retriever device. A recent meta-analysis investigated the use of IA thrombolysis after full dose IV tPA $(0.9 \mathrm{mg} / \mathrm{kg})$ and suggested that this method of combined treatment is safe and associated with higher recanalization rates and better functional outcome at 3 months. ${ }^{48}$

\section{ENDOVASCULAR THROMBUS REMOVAL}

Intra-arterial thrombus removal with the Penumbra aspiration system or Concentric MERCI device is reasonable in selected patients with major stroke where care has been initiated at $<8 \mathrm{~h}$ duration although data regarding improvement of clinical outcomes is unclear (AHA Class IIa, Level of Evidence B, CEBM level 2a, grade B).

Rapid clot extraction enabling prompt cerebral reperfusion has obvious appeal as a technique for ischemic stroke treatment. This treatment is theoretically ideal for those occlusions of cardioembolic origin, with well organized platelet poor thrombus and extensive fibrin cross linking that is refractory to chemical lysis. The two FDA cleared devices for endovascular clot removal are the MERCI Retrieval System (Concentric Medical Inc, Mountain View, California, USA) and the Penumbra stroke system (Penumbra Inc, Alameda, California, USA). The MERCI device was specifically designed and tested for extracting clots from major cerebral arteries, such as the distal internal carotid artery, the M1 segment of the middle cerebral and the vertebrobasilar arteries. Clots located in more distal cerebral arteries, like the posterior cerebral arteries, distal segments of the middle cerebral arteries or the anterior cerebral arteries are usually not accessible with the MERCI device and the risks of aggressive distal cerebrovascular instrumentation may not be justified by the potential clinical benefit. The safety and efficacy of the MERCI retrieval device for thrombus retrieval was tested in two prospective, single arm, multicenter trials conducted in the USA and led to FDA approval for clot retrieval in the presence of acute stroke. ${ }^{49}$ However, the approval has been criticized by stroke specialists because neither of the two conducted clinical trials evaluating the MERCI retrieval device were designed to prove its clinical efficacy for stroke therapy. ${ }^{50}$ Similarly, the Penumbra pivotal trial was a prospective, single cohort, phase 2 study to evaluate the safety and effectiveness of the Penumbra system aspiration catheter in 125 patients with moderate to severe acute stroke due to large vessel occlusion. The FDA approved Penumbra system is an aspiration catheter with a clot separator wire. While the study results showed an unusually high rate of recanalization, only $25 \%$ of patients had a good 90 day clinical outcome as defined by a modified Rankin Scale score of $\leq 2$, an outcome that is no better than the natural history of untreated acute stroke patients. ${ }^{21}$ Subsequent pooled analysis of the MERCI data, however, found that target vessel recanalization was the strongest predictor of outcomes, ${ }^{51}$ which corroborates findings in IMS I and II. 


\section{OTHER ENDOVASCULAR APPROACHES}

The usefulness of other endovascular devices is not yet established, but they may be beneficial and may be considered (AHA Class IIb, Level of Evidence C, CEBM level 4, grade C.)

Angioplasty alone and stent assisted angioplasty have been described, in retrospective series, for the past decade in the treatment of acute cerebral stroke, more recently using existing self-expanding stents approved for stent assisted coil embolization and intracranial atherosclerosis. ${ }^{52-55}$ Despite a relatively high technical success rate, there are potential immediate and delayed complications of permanent stent placement in acute stroke. The additional risk of hemorrhagic stroke transformation with ongoing antiplatelet therapy is not well defined. Likewise, the incidence of in-stent restenosis, which affects at least $30 \%$ of cerebral arteries stented for intracranial atherosclerosis, is not known for intracranial stents implanted for recanalization of acute thrombus. ${ }^{56}$ A single arm, prospective, FDA approved trial, Stent Assisted Recanalization in Acute Stroke (SARIS), reported data in 20 patients that supports the relative safety and angiographic efficacy of primary stenting in acute stroke. ${ }^{57}$ Closed cell stent designs allow for resheathing of self-expanding stents, after partial or even full deployment, resulting in a retrievable stent that functions to restore flow temporarily. ${ }^{58}$ While this may represent a new direction for acute stroke intervention, the concurrent use of anticoagulant, antiaggregating and thrombolytic medications requires further investigation before the routine implementation of this treatment strategy.

\section{POSTERIOR CIRCULATION}

The usefulness of endovascular treatment in the posterior circulation is not yet established, but it may be beneficial and may be considered, even beyond the 6-8h time window typical for anterior circulation stroke (AHA Class IIB, Level of Evidence C).

Recanalization rates and outcomes in basilar artery occlusion vary widely for both IA and IV thrombolysis, which is likely due to the wide clinical presentation and differing mechanisms and severity of underlying disease. ${ }^{59}$ Although occlusion of the basilar artery accounts for only $6-10 \%$ of large vessel strokes in humans, several meta-analyses have found that failure to recanalize an occluded basilar artery almost universally results in a poor clinical outcome. ${ }^{59}$ Failure of recanalization, coma at presentation, as well as a proximal location of thrombus have been found to be associated with higher mortality rates. ${ }^{61}$ Recanalization rates of over $50 \%$ have been achieved with both IA and IV thrombolysis in meta-analyses of multiple case series. ${ }^{59}{ }^{62}$ A single large prospective registry, the Basilar Artery International Cooperation Study (BASICS), found that in an analysis of 592 patients, $38 \%$ of patients were treated $>7 \mathrm{~h}$ after ictus either with antithrombotics, IV thrombolysis or IA therapy. In this cohort of patients, endovascular therapy did not show superiority over IV thrombolysis in terms of mortality or dependency, after adjusting for multiple factors such as age, stroke severity score and location of the occlusion. ${ }^{63}$ In the clinical trials of the MERCI and Penumbra thrombus removal devices, posterior circulation occlusions were included and treated with the same time parameters as the anterior circulation occlusion (up to $8 \mathrm{~h}$ following ictus) and were found to have similar recanalization rates. ${ }^{20} 21$ Due to the relatively rare nature of basilar artery occlusion, the poor prognosis and the paucity of prospective data, the rationale for aggressive treatment has been based largely on expert opinion, case series and meta-analyses. ${ }^{64}$

\section{ADJUNCTIVE THERAPY}

Systemic anticoagulation with heparin reduces the risk of catheter related embolism and augments the thrombolytic effect of some agents such as the now infrequently used r-proUK. Another rationale for antithrombotic therapy is prevention of acute re-occlusion. These indications are counterbalanced by the potentially increased risk of brain hemorrhage when heparin is combined with a thrombolytic agent. There is no standard heparin regimen established for IA thrombolysis in acute stroke. Data from the MultiMERCI trial indicates that rates of hemorrhage were not increased when heparin was used. ${ }^{65}$ PROACT- ${ }^{18}$ reported a $27 \%$ rate of symptomatic brain hemorrhage with a heparin regimen of $100 \mathrm{U} / \mathrm{kg}$ bolus and $1000 \mathrm{U} / \mathrm{h}$ for $4 \mathrm{~h}$ used with IA r-proUK. Subsequently, a low dose heparin regimen was used in the PROACT studies (2000 $\mathrm{U}$ bolus and $500 \mathrm{U} / \mathrm{h}$ for $4 \mathrm{~h}$ ), which reduced the symptomatic brain hemorrhage rate to $7 \%$ in PROACT-I and to $10 \%$ in PROACTII. ${ }^{19}$ GP IIb/IIIa inhibitors have never been studied in a randomized trial of IA thrombolysis in acute stroke but have been used anecdotally to treat re-occlusion and may be necessary during stent placement in the treatment of acute stroke, although dosing and route of administration are variable. A randomized, dose escalation study of IV abciximab in AIS (not exceeding approved doses for coronary intervention) suggested relative safety up to $24 \mathrm{~h}$ after onset, although there were nondose related asymptomatic intracranial hemorrhages. ${ }^{66}$ Use of the IIb/IIIa inhibitor abciximab for the IV treatment of acute stroke did not demonstrate either safety or efficacy compared with placebo in the phase III trial, Abciximab in Emergency Treatment of Stroke Trial (AbESTT-II). ${ }^{67}$

\section{THROMBOLYTIC AGENTS}

All thrombolytic agents are plasminogen activators and convert plasminogen to its active agent plasmin. rt-PA (alteplase) and rproUK are the best characterized in the treatment of AIS. ${ }^{18} 1923$ Newer agents such as tenecteplase, reteplase, plasmin and microplasmin, and combination therapies to improve efficacy of clot lysis (fibrinolytics and GP IIb/IIIa agents, and fibrinolytics and direct thrombin inhibitors) remain investigational. ${ }^{6-70}$ Desmoteplase, a fibrin selective plasminogen activator, initially thought to have promise as an IV thrombolytic, showed no benefit over placebo in a phase III trial targeting an imaging defined ischemic penumbra. ${ }^{71}$ Although some drugs may have differences in systemic effects and hemorrhagic complications, it remains unknown whether one thrombolytic agent is superior to another in terms of revascularization of AIS. Only IV rt-PA is FDA approved for the treatment of acute stroke and all thrombolytics are off-label when administered IA.

\section{IMAGING}

Imaging recommendations for treatment of acute stroke are included in the AHA guidelines for the early management of adults with ischemic stroke. ${ }^{1}$ Imaging is a class I recommendation and in most cases a non-contrast head CT will provide sufficient information to guide emergent management decisions; the initial imaging evaluation is required to exclude the presence of hemorrhage or other mass lesion mimicking ischemic stroke. ${ }^{72}$ There is no Class I evidence not to treat based on other CT findings, ${ }^{1}$ although some findings have been associated with poorer outcomes, such as the Alberta Stroke Program Early CT Score (ASPECTS), which has been shown to predict outcome in thrombolysis treated stroke patients with signs of acute ischemia on $\mathrm{CT}^{73}$ The acquisition of vascular imaging, whether 
CT angiography or MR angiography images with concomitant perfusion imaging during acute stroke, has been shown to be achievable in a reasonable time frame ( $<15 \mathrm{~min}$ imaging time for MRI; 10 min for CT).$^{74} 75$ CT angiography and MR angiography can be useful to triage patients in terms of large vessel versus small vessel disease and, therefore, to amend treatment options. For this reason, the availability of multimodality vascular imaging in acute stroke has been suggested as a quality metric for a CSC. ${ }^{76}$ Using CT or MR perfusion to identify patients with a mismatch of infarct core and ischemic penumbra, in theory, may allow improved patient selection and/or extension of current treatment time windows and is currently an intense area of research.

The Diffusion and Perfusion Imaging Evaluation for Understanding Stroke Evolution (DEFUSE) investigators noted significant increased odds of achieving a favorable clinical response in patients with MRI defined perfusion/diffusion mismatch treated with IV thrombolysis in the $3-6 \mathrm{~h}$ window. ${ }^{78}$ However, Desmoteplase in Acute Ischemic Stroke Trial II (DIASII), the only randomized trial using an ischemic penumbra defined by perfusion imaging to select patients for IV thrombolysis, failed to demonstrate benefit of desmoteplase over placebo in the $3-9 \mathrm{~h}$ window. ${ }^{71}$

In 2010, a technology assessment subcommittee of the American Academy of Neurology concluded that there was insufficient evidence to support the routine use of perfusion imaging in the triage of acute stroke patients in the diagnosis of acute stroke. ${ }^{79}$ Current evidence states that diffusion weighted imaging is superior to CT for the diagnosis of AIS and indicates that, in anterior circulation stroke, the initial infarct core volume is the best predictor of response to acute stroke therapy. ${ }^{79}$ Studies designed to determine defining thresholds for futile revascularization and poor outcome have indicated that an ASPECT score of $\leq 7$ and a diffusion weighted imaging core infarct volume of $\geq 70-100 \mathrm{ml}$ are more frequently associated with poor clinical results. ${ }^{73} 80-83$

\section{CONCLUSION}

AIS secondary to large vessel occlusion is a potentially devastating disease for which best treatment remains elusive. Recanalization efficacy and safety has been shown for IA thrombolysis and some thrombectomy devices. Randomized controlled trials have demonstrated clinical efficacy for IA thrombolysis in selected patients with acute middle cerebral artery occlusion. The desire to promote and popularize existing treatment options and exciting new devices or techniques must be tempered by the realization that the clinical efficacy of some treatment methods remains incompletely understood and warrants ongoing scientific and clinical research. To promote best possible clinical practice, the administration of interventional stroke treatment should remain in the hands of experienced stroke experts who should maximize data collection to achieve the best possible patient outcomes.

\section{Author affiliations}

'Department of Radiology, University Hospitals of Cleveland, Case Western Reserve University, Cleveland, Ohio, USA

${ }^{2}$ Department of Radiology and Neurological Surgery, Columbia University, College of Physicians and Surgeons Director, Neuroendovascular Service New York Presbyterian - Columbia, Neurological Institute of New York, New York, USA

${ }^{3}$ University of Cincinnati Medical Center, Cincinnati, OH, USA

${ }^{4}$ Division of Neurological Surgery, Barrow Neurosurgical Associates LTD, Phoenix, AZ, USA

${ }^{5}$ Department of Neurological Surgery, Stony Brook University Medical Center, Stony Brook, New York, USA

${ }^{6}$ Department of Neurological Surgery, University of Kentucky, Lexington, KY, USA
${ }^{7}$ Interventional Neuroradiology, Radiology Imaging Associates, Englewood, CO, USA ${ }^{8}$ Department of Neurological Surgery, UMDNJ-New Jersey Medical School, Newark, NJ, USA

${ }^{9}$ Department of Radiology, Forsyth Radiological Associates, Winston Salem, NC, USA ${ }^{10}$ Neurolnterventional Radiology, Massachusetts General Hospital, Boston, MA, USA

${ }^{11}$ Warren Alpert School of Medicine at Brown University, Director, Interventional Neuroradiology, Rhode Island Hospital, USA

${ }^{12}$ Deparments of Neurosurgery and Neurology, Wayne State University/Detroit Medical Center, Detroit, MI, USA

${ }^{13}$ Department of Neurological Surgery, University of Medicine and Dentistry of New Jersey, Newark, NJ, USA

Acknowledgments The authors would like to thank and acknowledge all members of the SNIS Executive Committee for their review and endorsement of this guidelines document.

\section{Competing interests None.}

Provenance and peer review Commissioned; not externally peer reviewed

\section{REFERENCES}

1. Adams HP Jr, del Zoppo G, Alberts MJ, et al. Guidelines for the early management of adults with ischemic stroke: a guideline from the American Heart Association/ American Stroke Association Stroke Council, Clinical Cardiology Council, Cardiovascular Radiology and Intervention Council, and the Atherosclerotic Peripheral Vascular Disease and Quality of Care Outcomes in Research Interdisciplinary Working Groups: The American Academy of Neurology affirms the value of this guideline as an educational tool for neurologists. Circulation 2007;115 e478-534

2. Meyers PM, Schumacher HC, Higashida RT, et al. Indications for the performance of intracranial endovascular neurointerventional procedures: a scientific statement from the American Heart Association Council on Cardiovascular Radiology and Intervention, Stroke Council, Council on Cardiovascular Surgery and Anesthesia, Interdisciplinary Council on Peripheral Vascular Disease, and Interdisciplinary Council on Quality of Care and Outcomes Research. Circulation 2009;119 2235-49.

3. Lloyd-Jones D, Adams R, Carnethon M, et al. Heart disease and stroke statistics - 2009 update: a report from the American Heart Association Statistics Committee and Stroke Statistics Subcommittee. Circulation 2009;119:e21-181.

4. Sacco RL, Benjamin EJ, Broderick JP, et al. American Heart Association Prevention Conference. IV. Prevention and rehabilitation of stroke. Risk factors. Stroke 1997;28:1507-17.

5. Adelman SM. The National Survey of Stroke. Economic impact. Stroke 1981;12 (Suppl 1):I69-87.

6. Taylor TN, Davis PH, Torner JC, et al. Lifetime cost of stroke in the United States. Stroke 1996;27:1459-66.

7. Rosamond W, Flegal K, Friday G, et al. Heart disease and stroke statistics-2007 update: a report from the American Heart Association Statistics Committee and Stroke Statistics Subcommittee. Circulation 2007;115:e69-171.

8. Cloft HJ, Rabinstein A, Lanzino G, et al. Intra-arterial stroke therapy: an assessment of demand and available work force. AJNR Am J Neuroradiol 2009;30:453-8.

9. Hirsch JA, Yoo AJ, Nogueira RG, et al. Case volumes of intra-arterial and intravenous treatment of ischemic stroke in the USA. J Neurointerv Surg 2009;1:27-31.

10. Meyers PM, Schumacher HC, Alexander MJ, et al. Performance and training standards for endovascular ischemic stroke treatment. J Neurointerv Surg 2009:1:10-12.

11. Standard for the Performance of Diagnostic Cervicocerebral Angiography in Adults, in ACR Practice Guidelines. Reston, VA: American College of Radiology, 2006 71-85.

12. Gomez C, Kinkel P, Masdeu J, et al. American Academy of Neurology guidelines for credentialing in neuroimaging. Report from the task force on updating guidelines for credentialing in neuroimaging. Neurology 1997;49:1734-7.

13. Anon. Quality improvement guidelines for adult diagnostic neuroangiography. Cooperative study between the ASNR, ASITN, and the SCVIR. AJNR Am J Neuroradiol 2000;21:146-50.

14. Sackett DL. Rules of evidence and clinical recommendations on the use of antithrombotic agents. Chest 1986;89(2 Suppl):2S-3S.

15. Gibbons RJ, Smith SC Jr, Antman E; American College of Cardiology; American Heart Association. American College of Cardiology/American Heart Association clinical practice guidelines: Part II: evolutionary changes in a continuous quality improvement project. Circulation 2003;107:3101-7.

16. Gibbons RJ, Smith S, Antman E; American College of Cardiology; American Heart Association. American College of Cardiology/American Heart Association clinical practice guidelines: Part I: where do they come from? Circulation 2003;107:2979-86

17. OCEBM Levels of Evidence Working Group. The Oxford 2011 Levels of Evidence Oxford Centre for Evidence-Based Medicine. http://www.cebm.net/index.aspx? $0=5653$ (accessed 1 Sep 2011)

18. del Zoppo GJ, Higashida RT, Furlan AJ, et al. PROACT: a phase II randomized trial of recombinant pro-urokinase by direct arterial delivery in acute middle cerebral artery 
stroke. PROACT Investigators. Prolyse in Acute Cerebral Thromboembolism. Stroke 1998;29:4-11

19. Furlan A, Higashida R, Wechsler L, et al. Intra-arterial prourokinase for acute ischemic stroke. The PROACT II study: a randomized controlled trial. Prolyse in Acute Cerebral Thromboembolism. JAMA 1999;282:2003-11.

20. Smith WS, Sung G, Starkman S, et al. Safety and efficacy of mechanical embolectomy in acute ischemic stroke: results of the MERCI trial. Stroke 2005;36:1432-8

21. Penumbra Pivotal Stroke Trial Investigators. The penumbra pivotal stroke tria safety and effectiveness of a new generation of mechanical devices for clot removal in intracranial large vessel occlusive disease. Stroke 2009;40:2761-8.

22. Saqqur M, Uchino K, Demchuk AM, et al. Site of arterial occlusion identified by transcranial Doppler predicts the response to intravenous thrombolysis for stroke. Stroke 2007;38:948-54.

23. Hacke W, Kaste M, Bluhmki E, et al. Thrombolysis with alteplase 3 to 4.5 hours after acute ischemic stroke. N Engl J Med 2008;359:1317-29.

24. Wahlgren $\mathbf{N}$, Ahmed N, Eriksson N, et al. Multivariable analysis of outcome predictors and adjustment of main outcome results to baseline data profile in randomized controlled trials: Safe Implementation of Thrombolysis in StrokeMOnitoring STudy (SITS-MOST). Stroke 2008:39:3316-22.

25. Anon. Tissue plasminogen activator for acute ischemic stroke. The National Institute of Neurological Disorders and Stroke rt-PA Stroke Study Group. N Engl J Med 1995; 333:1581-7.

26. Del Zoppo GJ, Saver JL, Jauch EC, et al. Expansion of the time window for treatment of acute ischemic stroke with intravenous tissue plasminogen activator: a science advisory from the American Heart Association/American Stroke Association. Stroke 2009;40:2945-8.

27. Albers GW, Amarenco P. Easton JD, et al. Antithrombotic and thrombolytic therapy for ischemic stroke: the Seventh ACCP Conference on Antithrombotic and Thrombolytic Therapy. Chest 2004;126(3 Suppl):483S-512S.

28. Wahlgren N, Ahmed N, Dávalos A, et al. Thrombolysis with alteplase for acute ischaemic stroke in the Safe Implementation of Thrombolysis in Stroke-Monitoring Study (SITS-MOST): an observational study. Lancet 2007;369:275-82.

29. Riedel CH, Zimmermann P, Jensen-Kondering U, et al. The importance of size: successful recanalization by intravenous thrombolysis in acute anterior stroke depends on thrombus length. Stroke 2011:42:1775-7.

30. Alberts MJ, Latchaw RE, Selman WR, et al. Recommendations for comprehensive stroke centers: a consensus statement from the Brain Attack Coalition. Stroke 2005:36:1597-616.

31. Schwamm LH, Pancioli A, Acker JE 3rd, et al. Recommendations for the establishment of stroke systems of care: recommendations from the American Stroke Association's Task Force on the Development of Stroke Systems. Stroke 2005; 36:690-703

32. George MG, Tong $X, M c G r u d e r ~ H$, et al. Paul Coverdell National Acute Stroke Registry Surveillance - four states, 2005-2007. MMWR Surveill Summ 2009;58:1-23

33. Schwamm LH, Fonarow GC, Reeves MJ, et al. Get with the Guidelines-Stroke is associated with sustained improvement in care for patients hospitalized with acute stroke or transient ischemic attack. Circulation 2009;119:107-15.

34. Alberts MJ, Latchaw RE, Jagoda A, et al. Revised and updated recommendations for the establishment of primary stroke centers: a summary statement from the brain attack coalition. Stroke 2011;42:2651-65.

35. Nogueira RG, Schwamm LH, Hirsch JA, et al. Endovascular approaches to acute stroke, part 1: Drugs, devices, and data. AJNR Am J Neuroradiol 2009; 30:649-61.

36. Lee M, Hong KS, Saver JL, et al. Efficacy of intra-arterial fibrinolysis for acute ischemic stroke: meta-analysis of randomized controlled trials. Stroke 2010:41:932-7.

37. Lisboa RC, Jovanovic BD, Alberts MJ, et al. Analysis of the safety and efficacy of intra-arterial thrombolytic therapy in ischemic stroke. Stroke 2002;33:2866-71.

38. Rha JH, Saver JL. The impact of recanalization on ischemic stroke outcome: a metaanalysis. Stroke 2007;38:967-73.

39. Bourekas EC, Slivka AP, Shah R, et al. Intraarterial thrombolytic therapy within 3 hours of the onset of stroke. Neurosurgery 2004:54:39-44.

40. Moazami N, Smedira NG, McCarthy PM, et al. Safety and efficacy of intraarterial thrombolysis for perioperative stroke after cardiac operation. Ann Thorac Surg 2001:72:1933-7.

41. Mathews MS, Sharma J, Snyder KV, et al. Safety, effectiveness, and practicality of endovascular therapy within the first 3 hours of acute ischemic stroke onset. Neurosurgery 2009;65:860-5

42. Lewandowski CA, Frankel M, Tomsick TA, et al. Combined intravenous and intraarterial r-TPA versus intra-arterial therapy of acute ischemic stroke: Emergency Management of Stroke (EMS) Bridging Trial. Stroke 1999;30:2598-605.

43. IMS Study Investigators. Combined intravenous and intra-arterial recanalization for acute ischemic stroke: the Interventional Management of Stroke Study. Stroke 2004;35:904-11.

44. IMS II Trial Investigators. The Interventional Management of Stroke (IMS) || Study. Stroke 2007:38:2127-35.

45. Wolfe T, Suarez JI, Tarr RW, et al. Comparison of combined venous and arterial thrombolysis with primary arterial therapy using recombinant tissue plasminogen activator in acute ischemic stroke. J Stroke Cerebrovasc Dis 2008; 17:121-8
46. Zaidat 00. Suarez JI, Santillan C, et al. Response to intra-arterial and combined intravenous and intra-arterial thrombolytic therapy in patients with distal internal carotid artery occlusion. Stroke 2002;33:1821-6.

47. Han MK, Kim SH, Ko SB, et al. Combined intravenous and intraarterial revascularization therapy using MRI perfusion/diffusion mismatch selection for acute ischemic stroke at 3-6 h after symptom onset. Neurocrit Care 2008:8:353-9.

48. Georgiadis AL, Memon MZ, Shah QA, et al. Comparison of partial $(.6 \mathrm{mg} / \mathrm{kg})$ versus full-dose $(.9 \mathrm{mg} / \mathrm{kg})$ intravenous recombinant tissue plasminogen activator followed by endovascular treatment for acute ischemic stroke: a meta-analysis. $J$ Neuroimaging 2011;21:113-20.

49. Food and Drug Administration. Final Decision 510(k) for Concentric Merci(R) Retriever, August 11, 2004. http://www.fda.gov/cdrh/pdf3/k033736.pdf laccessed 1 Feb 2005)

50. Becker KJ, Brott TG. Approval of the MERCl clot retriever: a critical view. Stroke 2005:36:400-3.

51. Nogueira RG, Liebeskind DS, Sung G, et al. Predictors of good clinical outcomes, mortality, and successful revascularization in patients with acute ischemic stroke undergoing thrombectomy: pooled analysis of the Mechanical Embolus Removal in Cerebral Ischemia (MERCI) and Multi MERCI Trials. Stroke 2009;40:3777-83.

52. Kelly ME, Furlan AJ, Fiorella D. Recanalization of an acute middle cerebral artery occlusion using a self-expanding, reconstrainable, intracranial microstent as a temporary endovascular bypass. Stroke 2008;39:1770-3.

53. Levy El, Mehta R, Gupta R, et al. Self-expanding stents for recanalization of acute cerebrovascular occlusions. AJNR Am J Neuroradiol 2007;28:816-22.

54. Lum C, Stys PK, Hogan MJ, et al. Acute anterior circulation stroke: recanalization using clot angioplasty. Can J Neurol Sci 2006:33:217-22.

55. Nogueira RG, Schwamm LH, Buonanno FS, et al. Low-pressure balloon angioplasty with adjuvant pharmacological therapy in patients with acute ischemic stroke caused by intracranial arterial occlusions. Neuroradiology 2008;50:331-40

56. Fiorella DJ, Levy El, Turk AS, et al. Target lesion revascularization after wingspan assessment of safety and durability. Stroke 2009:40:106-10.

57. Levy El, Siddiqui AH, Crumlish A, et al. First Food and Drug Administration-approved prospective trial of primary intracranial stenting for acute stroke: SARIS (stentassisted recanalization in acute ischemic stroke). Stroke 2009:40:3552-6.

58. Miteff F, Faulder KC, Goh AC, et al. Mechanical thrombectomy with a self-expanding retrievable intracranial stent (Solitaire AB): experience in 26 patients with acute cerebral artery occlusion. AJNR Am J Neuroradiol 2011:32:1078-81.

59. Lindsberg PJ, Mattle HP. Therapy of basilar artery occlusion: a systematic analysis comparing intra-arterial and intravenous thrombolysis. Stroke 2006:37:922-8.

60. Hacke W, Zeumer $\mathrm{H}$, Ferbert A, et al. Intra-arterial thrombolytic therapy improves outcome in patients with acute vertebrobasilar occlusive disease. Stroke 1988:19:1216-22.

61. Levy El, Firlik $A D$, Wisniewski $S$, et al. Factors affecting survival rates for acute vertebrobasilar artery occlusions treated with intra-arterial thrombolytic therapy: a meta-analytical approach. Neurosurgery 1999;45:539-45.

62. Smith WS. Intra-arterial thrombolytic therapy for acute basilar occlusion: pro. Stroke 2007:38(2 Suppl):701-3.

63. Schonewille WJ, Wijman CA, Michel P, et al. Treatment and outcomes of acute basilar artery occlusion in the Basilar Artery International Cooperation Study (BASICS): a prospective registry study. Lancet Neurol 2009:8:724-30.

64. Nogueira RG, Yoo AJ, Buonanno FS, et al. Endovascular approaches to acute stroke, part 2: a comprehensive review of studies and trials. AJNR Am J Neuroradio 2009:30:859-75

65. Nahab F, Walker GA, Dion JE, et al. Safety of periprocedural heparin in acute ischemic stroke endovascular therapy: The multi MERCI trial. J Stroke Cerebrovasc Dis. Published Online First: 1 June 2011. doi:10.1016/.j.jstrokecerebrovasdis.2011.04.009.

66. Anon. Abciximab in acute ischemic stroke: a randomized, double-blind, placebocontrolled, dose-escalation study. The Abciximab in Ischemic Stroke Investigators. Stroke 2000;31:601-9.

67. Adams $\mathbf{H P} \mathbf{J r}$, Effron MB, Torner J, et al. Emergency administration of abciximab for treatment of patients with acute ischemic stroke: results of an international phase II trial: Abciximab in Emergency Treatment of Stroke Trial (AbESTT-II). Stroke 2008:39:87-99.

68. Molina CA, Saver JL. Extending reperfusion therapy for acute ischemic stroke: emerging pharmacological, mechanical, and imaging strategies. Stroke 2005; 36:2311-20.

69. Qureshi Al, Ali Z, Suri MF, et al. Intra-arterial third-generation recombinant tissue plasminogen activator (reteplase) for acute ischemic stroke. Neurosurgery 2001:49:41-8.

70. Haley EC Jr, Thompson JL, Grotta JC, et al. Phase IIB/III trial of tenecteplase in acute ischemic stroke: results of a prematurely terminated randomized clinical trial. Stroke 2010:41:707-11

71. Hacke W, Furlan AJ, Al-Rawi Y, et al. Intravenous desmoteplase in patients with acute ischaemic stroke selected by MRI perfusion-diffusion weighted imaging or perfusion CT (DIAS-2): a prospective, randomised, double-blind, placebo-controlled study. Lancet Neurol 2009;8:141-50.

72. von Kummer R. Early major ischemic changes on computed tomography should preclude use of tissue plasminogen activator. Stroke 2003:34:820-1.

73. Barber PA, Demchuk AM, Zhang J, et al. Validity and reliability of a quantitative computed tomography score in predicting outcome of hyperacute stroke before thrombolytic therapy. ASPECTS Study Group. Alberta Stroke Programme Early CT Score. Lancet 2000;355:1670-4. 
74. Sunshine JL, Tarr RW, Lanzieri CF, et al. Hyperacute stroke: ultrafast MR imaging to triage patients prior to therapy. Radiology 1999;212:325-32.

75. Wintermark M, Reichhart M, Cuisenaire 0 , et al. Comparison of admission perfusion computed tomography and qualitative diffusion- and perfusion-weighted magnetic resonance imaging in acute stroke patients. Stroke 2002; 33:2025-31.

76. Heidenreich J0, Hsu D, Wang G, et al. Magnetic resonance imaging results can affect therapy decisions in hyperacute stroke care. Acta Radiol 2008;49:550-7.

77. Leifer D, Bravata DM, Connors J J $3 r d$, et al. Metrics for measuring quality of care in comprehensive stroke centers: detailed follow-up to Brain Attack Coalition comprehensive stroke center recommendations: a statement for healthcare professionals from the American Heart Association/American Stroke Association. Stroke 2011:42:849-77.

78. Albers GW, Thijs VN, Wechsler L, et al. Magnetic resonance imaging profiles predict clinical response to early reperfusion: the diffusion and perfusion imaging evaluation for understanding stroke evolution (DEFUSE) study. Ann Neurol 2006;60:508-17.
79. Schellinger PD, Bryan RN, Caplan LR, et al. Evidence-based guideline: The role of diffusion and perfusion MRI for the diagnosis of acute ischemic stroke: report of the Therapeutics and Technology Assessment Subcommittee of the American Academy of Neurology. Neurology 2010;75:177-85.

80. Yoo AJ, Verduzco LA, Schaefer PW, et al. MRI-based selection for intra-arterial stroke therapy: value of pretreatment diffusion-weighted imaging lesion volume in selecting patients with acute stroke who will benefit from early recanalization. Stroke 2009; 40:2046-54.

81. Jovin TG, Yonas $\mathrm{H}$, Gebel JM, et al. The cortical ischemic core and not the consistently present penumbra is a determinant of clinical outcome in acute middle cerebral artery occlusion. Stroke 2003;34:2426-33.

82. Thomalla GJ, Kucinski T, Schoder V et al. Prediction of malignant middle cerebra artery infarction by early perfusion- and diffusion-weighted magnetic resonance imaging. Stroke 2003;34:1892-9.

83. Mlynash M, Lansberg MG, De Silva DA, et al. Refining the definition of the malignant profile: insights from the DEFUSE-EPITHET pooled data set. Stroke $2011 \cdot 42 \cdot 1270-5$

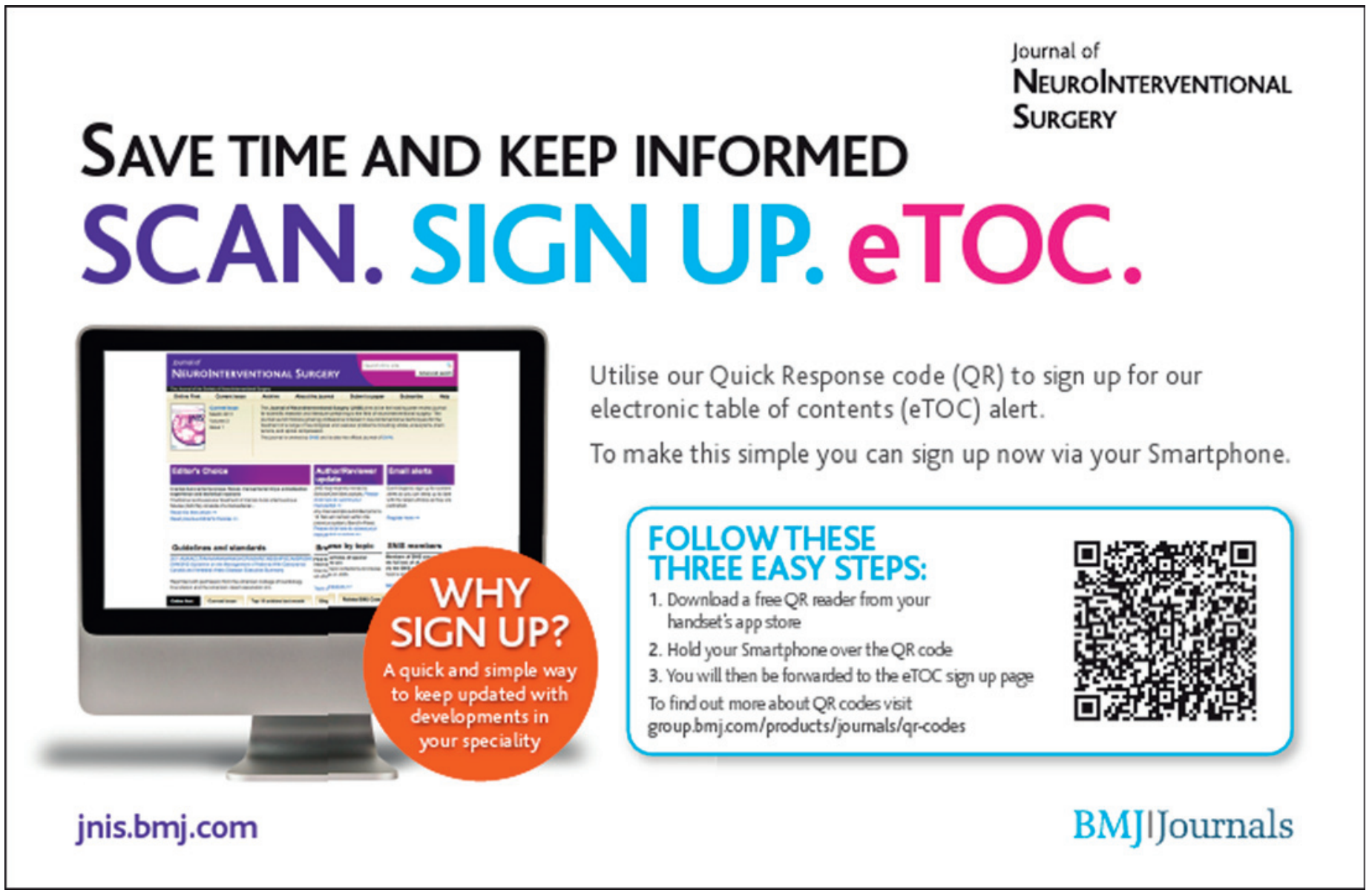


7. Alaraj A, Wallace A, Mander N, et al. Outcome following symptomatic cerebral vasospasm on presentation in aneurysmal subarachnoid hemorrhage: coiling vs clipping. World Neurosurg 2010;74:138-42.

8. Wikholom G, Lindgren $\mathrm{H}$, Rodriguez $\mathrm{H}$, et al. Embolization with Guglielmi detachable coils during the period of increased risk for cerebral vasospasm: early outcome. Neuroradiology 2000:42:833-7.

9. Murayama Y, Malisch T, Guglielmi G, et al. Incidence of cerebral vasospasm after endovascular treatment of acutely ruptured aneurysms: report on 69 cases. $J$ Neurosurg 1997:87:830-5.

10. Morizane A, Nakahara I, Sakai N, et al. Endovascular surgery for treated aneurysm with symptomatic vasospasm. No Shinkei Geka 1999;27:941-6.

11. Murayama Y, Song JK, Uda K, et al. Combined endovascular treatment for both intracranial aneurysm and symptomatic vasospasm. AJNR Am J Neuroradiol 2003;24:133-9

12. Sugiu K, Katsumata A, Ono $\mathrm{Y}$, et al. Angioplasty and coiling of ruptured aneurysm with symptomatic vasospasm: technical case report. Surg Neurol 2003;59:413-17.

13. Tosaka M, Okajima F, Hashiba Y, et al. Sphingosine 1-phosphate contracts canine basilar arteries in vitro and vivo. Possible role in pathogenesis of cerebral vasospasms. Stroke 2001;32:2913-19.

14. Shibuya M, Suzuki Y, Sugita K, et al. Effect of AT877 on cerebral vasospasm after aneurismal hemorrhage. J Neurosurg 1992;76:572-7.

15. Kassell NF, Helm G, Simmons N, et al. Treatment of cerebral vasospasm with intraarterial papaverine. J Neurosurg 1992;77:848-52.

16. Wanke I, Dorfler A, Dietrich U, et al. Combined endovascular therapy of ruptured aneurysms and cerebral vasospasm. Neuroradiology 2000;42:926-9.

17. Hope JKA, Byrne JV, Molyneux AJ, et al. Factors influencing successful angiographic occlusion of aneurysms treated by coil embolization. AJNR Am J Neuroradiol 1999;20:391-9.

18. Byrne JV. Acute endovascular treatment by coil embolization of ruptured intracranial aneurysms. Ann R Coll Surg Engl 2001;83:253-7.

19. Kaku Y, Yonekawa Y, Tsukahara T, et al. Superselective intra-arterial infusion of papaverine for the treatment of cerebral vasospasm after subarachnoid hemorrhage. J Neurosurg 1992;77:842-7.
20. Terada T, Kinoshita $\mathrm{Y}$, Yokote $\mathrm{H}$, et al. The effect of endovascular therapy for cerebral arterial spasm, its limitations and pitfalls. Acta Neurochir (Wien) 1997; 139:227-34.

21. Clouston JE, Numaguchi $Y$, Zoarski GH, et al. Intraarterial papaverine infusion for cerebral vasospasm after subarachnoid hemorrhage. AJNR Am J Neuroradiol 1995:16:27-38.

22. Jin $\mathbf{Y}$, Sagher 0 , Thai $\mathrm{QA}$, et al. The effects of papaverine on phorbol dibutylate-induced vasoconstriction in brain slice microvessels. J Neurosurg 1994;81:574-8.

23. Clyde BL, Firlik AD, Kaufmann AM, et al. Paradoxical aggravation of vasospasm with papaverine infusion following aneurysmal subarachnoid hemorrhage. J Neurosurg 1996:84:690-5.

24. Biondi A, Ricciardi GK, Puybasset L, et al. Intra-arterial nimodipine for the treatment of symptomatic cerebral vasospasm after aneurysmal subarachnoid hemorrhage: preliminary results. AJNR Am J Neuroradiol 2004;25:1067-76.

25. Mayer TE, Dichagans M, Straube A, et al. Continuous intra-arterial nimodipine for the treatment of cerebral vasospasm. Cardiovasc Intervent Radiol 2008;31:1200-4.

26. Keuskamp J, Murali R, Chao KH, et al. High-dose intraarterial verapamil in the treatment of cerebral vasospasm after aneurysmal subarachnoid hemorrhage. $J$ Neurosurg 2008;108:458-63.

27. Albanese $\mathbf{E}$, Russo $A$, Quiroga $M$, et al. Ultrahigh-dose intraarterial verapamil in the treatment of cerebral vasospasm after aneurysmal subarachnoid hemorrhage. $J$ Neurosurg 2010:113:913-22.

28. Tachibana E, Harada T, Shibuya M, et al. Intra-arterial infusion of fasudil hydrochroride for treating vasospasm following subarachnoid haemorrhage. Acta Neurochirurgica (Wien) 1999;141:13-19.

29. Hanggi D, Beseoglu K, Turowski B, et al. Feasibility and safety of intrathecal nimodipine on posthaemorrhagic cerebral vasospasm refractory to medical therapy and endovascular therapy. Clin Neurol Neurosurg 2008;110:784-90.

30. Eskridge JM, McAuliffe W, Song JK, et al. Balloon angioplasty for the treatment of vasospasm: results of first 50 cases. Neurosurgery 1998;42:510-17.

31. Eskridge JM, Song JK, Elliott JP, et al. Balloon angioplasty of the A1 segment of the anterior cerebral artery narrowed by vasospasm. J Neurosurg 1999:91:153-6.

\section{Corrections}

Blackham KA, Meyers PM, Abruzzo TA, et al. Endovascular therapy of acute ischemic stroke: report of the Standards of Practice Committee of the Society of NeuroInterventional Surgery. J NeuroIntervent Surg 2012;4:87-93.

The following author's details should read: Albuquerque FC, Barrow Neurosurgical Associates LTD, Phoenix, AZ, USA.

J Neurolntervent Surg 2012:4:195. doi:10.1136/neurintsurg-2011-010243corr1

Meyers PM, Blackham KA, Abruzzo TA, Gandhi CD, Higashida RT, Hirsch JA, Hsu D, Moran CJ, Narayanan S, Prestigiacomo CJ, Tarr R. on behalf of the Society for NeuroInterventional Surgery. Society of NeuroInterventional Surgery Standards of Practice: general considerations. J NeuroIntervent Surg 2012;4:11-15. doi:10.1136/neurintsurg-2011010180 .

The following author has been added to the author list: Dr. Muhammad Shazam Hussein

J Neurolntervent Surg 2012:4:195. doi:10.1136/neurintsurg-2011-010180corr1

Eicker S, Etminan N, Turowski B, et al. Intracranial carotid artery stent placement causes delayed severe intracranial hemorrhage in a patient with moyamoya disease. J NeuroIntervent Surg 2011;3:160-162. doi:10.1136/jnis.2010.003004.

This article was published with the incorrect doi number. The correct doi number is: doi:10.1136/jnis.2010.3004.

J Neurolntervent Surg 2012:4:195. doi:10.1136/jnis.2010.3004 


\title{
Stent assisted coiling of the ruptured wide necked intracranial aneurysm
}

\author{
Y M Lodi, ${ }^{1,2}$ J G Latorre, ${ }^{3}$ Z El-Zammar, ${ }^{3}$ A Swarnkar, ${ }^{2}$ E Deshaies, ${ }^{1,2}$ R D Fessler ${ }^{4}$
}

'Department of Neurosurgery, SUNY Upstate Medical University, Syracuse, New York, USA

${ }^{2}$ Department of Radiology, SUNY Upstate Medical University, Syracuse, New York, USA

${ }^{3}$ Department of Neurology, SUNY Upstate Medical University, Syracuse, New York, USA

${ }^{4}$ Department of Neurosurgery, St John Main, Detroit, Michigan, USA

\section{Correspondence to} Professor Y M Lodi, Department of Neurology, Radiology and Neurosurgery, SUNY Upstate Medical University, $750 \mathrm{E}$

Adams Street, Syracuse, NY 13210, USA;

yahia25@hotmail.com

Received 28 March 2011 Revised 23 May 2011

Accepted 26 May 2011 Published Online First 18 July 2011

\section{ABSTRACT}

Background Stent assisted coiling of unruptured wide necked intracranial aneurysms require antiplatelets to prevent stent thrombosis. The effect of the loading dose of antiplatelets prior to the stent coiling procedure in an unsecured wide necked ruptured intracranial aneurysm is not known.

Objective To report any potential complication associated with the use of both aspirin and clopidogrel in stent assisted coiling of ruptured wide necked intracranial aneurysms.

Methods Consecutive patients who underwent stent assisted coiling for ruptured wide necked intracranial aneurysm were enrolled from 2005 to 2009. Patients' demographics, including Hunt and Hess grade, Fisher scale, and location and size of aneurysms, were collected. Complications such as rupture of aneurysm, thromboembolic events, ventriculostomy associated or systemic hemorrhages were recorded. Additionally, a 90 day outcome measurement was obtained using the Glasgow Outcome Scale.

Results 22 patients with a mean age of $50 \pm 13$ years underwent stent assisted coiling. A loading dose of clopidogrel $300 \mathrm{mg}$ and aspirin $325 \mathrm{mg}$ orally were given prior to stent placement. There was no intraoperative rupture of aneurysm, ventriculostomy associated hemorrhage or systemic hemorrhagic event. There were two episodes of stent thrombosis; one was an asymptomatic event which developed during the stent assisted coiling procedure and resolved spontaneously; the other was symptomatic which required intra-arterial administration of glycoprotein Ilbllla receptor antagonist. There was no mortality and good outcome was observed in $82 \%$ of patients.

Conclusion In our series of carefully selected patients, therapeutic dual antiplatelet loading prior to stent assisted coiling of ruptured wide necked intracranial aneurysm was not associated with increased bleeding complications. However, thromboembolic events remain the main challenge. Further study is required to confirm the safety of antiplatelet loading in stent assisted ruptured intracranial aneurysm coiling.

\section{INTRODUCTION}

The challenges of stent assisted treatment of complex intracranial aneurysm have been described in previous studies. Most of the data ${ }^{1-9}$ came from experiences of using Neuroform stents (Boston Scientific Target, Fremont, California, USA) which were approved by the Food and Drug Administration in 2002 under humanitarian device exemption. The Enterprise stent (Cordis Neurovascular, Miami, Florida, USA) is a relatively new intracranial stent approved by the Food and Drug Administration in 2007 under the guideline of humanitarian device exemption for the treatment of wide necked intracranial aneurysm. The uses of these types of stents have been associated with technical challenges, including difficulties in navigation of stent, imprecise placement of stent and stent migration. ${ }^{1-10}$ The technical challenge in navigation of stent in the intracranial circulation varies from $3 \%$ to $14.2 \%$, and the incidence of stent migration ranges from $1 \%$ to $16 \%$. The clinical complications associated with stents include intraoperative rupture of aneurysm and immediate or delayed thromboembolic events associated with stent. $^{1-8} 10$ The most common clinical complication is transient or permanent thromboembolic event related to intracranial stent, the incidence of which varies from $2 \%$ to $21 \%$. The second most common clinical complication is intraoperative rupture of aneurysm and hemorrhage that varies from $1.5 \%$ to $15 \%$. Most of the patients enrolled in the previous studies had unruptured wide necked aneurysms and the numbers of ruptured intracranial aneurysm patients were very small. However, two recent studies ${ }^{11}{ }^{12}$ enrolled many ruptured wide necked aneurysms but the results varied. Recently, two studies ${ }^{13} 14$ deliberately evaluated the risk and benefit of stent assisted repair of ruptured intracranial aneurysms. In both studies ${ }^{13} 14$ there was no preoperative standard antiplatelet regiment using aspirin and clopidogrel for the protection of stent. However, in one ${ }^{13}$ glycoprotein IlbIIIa receptor antagonist was administered intraoperatively prior to stent deployment.

Currently, there is no single study that has specifically used an antiplatelet regiment (both aspirin and clopidogrel) prior to the deployment of stent or evaluated the antiplatelet effect on hemorrhagic and thromboembolic complications in ruptured intracranial wide necked aneurysm. The objective of our study was to evaluate the safety, feasibility and outcome of patients who were treated with therapeutic doses of both aspirin and clopidogrel prior to stent assisted coiling of their ruptured intracranial aneurysm. Additionally, we tried to evaluate any hemorrhagic complications associated with the use of antiplatelets and placement of external ventricular drainage (EVD) catheter in our series.

\section{METHODS}

Data of patients undergoing stent assisted treatment of intracranial wide necked and fusiform aneurysms were prospectively collected and 
maintained in a database. Twenty-two consecutive patients who underwent stent assisted coiling of an intracranial ruptured wide necked aneurysm were selected and their data were retrospectively analyzed. Institutional Review Board approval was obtained prior to the treatment and retrieval of the data. The decision regarding surgical clipping versus endovascular stent assisted treatment of the aneurysm was made on the agreement between a vascular neurosurgeon and a neuroendovascular specialist. Additionally, prior to the selection of stent assisted repair, the treating endovascular operator thoroughly evaluated the architecture of the parent artery and ruled out any perceived difficulties in navigations through the blood vessels and catheterizations of the aneurysm.

The clinical severity of subarachnoid hemorrhage was assessed using the Hunt and Hess $(\mathrm{H} \& \mathrm{H})$ grade, and the radiographic grade was measured using the Fisher scale. Outcomes were predefined on the basis of radiographic and clinical criteria. Radiographic outcomes were defined as the rate of immediate occlusion (complete occlusion (100\%), near complete occlusion or neck remnant $(>95 \%$ but $<100 \%)$ or subtotal occlusion $<95 \%)$ after stent assisted coiling of the ruptured aneurysm. Clinical outcomes were measured using the Glasgow Outcome Scale (GOS). Outcome was defined as good if the obtained GOS was $\geq 4$ at the 90 day follow-up visit.

Wide necked aneurysm was defined as having a dome to neck ratio $<2$ or a neck $>4 \mathrm{~mm}$ in diameter. All patients with a ruptured aneurysm who underwent stent assisted repair were treated with both a loading dose of aspirin $325 \mathrm{mg}$ and clopidogrel $300 \mathrm{mg}$ at least $2 \mathrm{~h}$ prior to intended stent deployment. Patients were continued on both aspirin $325 \mathrm{mg}$ and clopidogrel $75 \mathrm{mg}$ daily for 4 weeks after the stenting procedure and thereafter on daily $325 \mathrm{mg}$ aspirin alone.

An EVD was placed if indicated prior to the procedure and initiation of antithrombotic medications to prevent potential bleeding complications related to ventriculostomy insertion. We also avoided postprocedural intravenous anticoagulation in subarachnoid hemorrhage patients to prevent potential bleeding complications associated with the ventriculostomy catheter. However, standard subcutaneous anticoagulation for the prevention of deep venous thrombosis was continued.

\section{Procedures}

Stent assisted coiling techniques have been described previously by us. ${ }^{7} 1516$ Briefly, a 6 F guiding catheter (Boston Scientific Target, Fremont, California, USA) flushed with continuous heparinized saline was placed in the proximal part of the vessel of interest (internal carotid, vertebral artery) and advanced through the guiding catheter under the guidance of fluoroscope and roadmaps. The aneurysm was crossed with a microcatheter (SL 10; Boston Scientific Target) and a microwire (Synchro 14 (Boston Scientific Target) or Transcend 14 (Cordis, Miami, Florida, USA)). The microcatheter was swapped with an exchange length microwire (X-celerator $300 \mathrm{~cm}$; eV3, Irvine, California, USA). Stent delivery system was prepared and advanced over the exchange length microwire as a unit and subsequently deployed across the neck of the aneurysm. Recently, we had begun to use a direct approach in which a $200 \mathrm{~cm} 0.014$ compatible microwire was back loaded through the stent delivery system and the stent delivery system was then advanced as a unit through the guiding catheter. For the Enterprise stent (Cordis Neurovascular), a 14 compatible microcatheter (Prowler select 14; Boston Scientific Target) was loaded over the microwire (Synchro 14; Boston Scientific Target) which was placed on the parent artery distal to the neck of the aneu- rysm. Placement of the microcatheter was confirmed with a microcatheter angiogram. Baseline serum activated coagulation time was obtained, and intravenous heparin was administered after placement of the stent delivery catheter in the parent artery distal to the aneurysm and just $5-10$ min prior to stent delivery to achieve an activated coagulation time of 1.5 times the baseline value. To cover the neck of the aneurysm adequately, the stent was deployed at least $4 \mathrm{~mm}$ proximal and $4 \mathrm{~mm}$ distal to the neck of the parent artery. The aneurysms in this series were catheterized by the direct approach in which the microcatheter was advanced through the interstiches of the Neuroform stent and Enterprise stent over a soft 14 compatible microwire (Synchro soft 14; Boston Scientific Target). Angiographic and clinical follow-up was planned for each patient at 3 , 12,18 and 36 months.

\section{Statistical analysis}

Patient demographics, including age, race, gender, cardiovascular risk factors, and location and size of aneurysm, were collected. A Student's t test of independent samples was performed to compare means, and either a Pearson $\chi^{2}$ test or Fisher's exact test was used to compare proportions. Univariate analysis was done to determine if there were clinical or patient characteristics associated with thromboembolic complications. Due to the low number of observed outcomes, multivariable analysis was not performed. All analyses were carried out using statistical software SAS V.9.1.3.

\section{RESULTS}

Twenty-two patients with a mean age of $50 \pm 13$ years underwent successful stent assisted coiling of ruptured wide necked intracranial aneurysms using 24 intracranial stents (Neuroform 14, Enterprise 10) (figures 1 and 2). The majority of the patients were female (19/22) and basilar artery bifurcation aneurysm was present in $11(50 \%)$ cases. A presenting $\mathrm{H} \& \mathrm{H}$ clinical grade I was observed in 11 patients, grade II in three patients, grade III in four patients and grade IV in four patients. A history of hypertension was present in 10/22, active smoking history in $11 / 22$ and a history of prior intracranial aneurysm was present in one patient. In our series, antiplatelet loading with clopidogrel $300 \mathrm{mg}$ and aspirin $325 \mathrm{mg}$ was given at least $2 \mathrm{~h}$ and not more than $3 \mathrm{~h}$ prior to stent deployment. Fifteen patients required EVD placements-in 13 cases the EVD was placed at least $6 \mathrm{~h}$ before the procedure and antithrombotic loading dose while in two cases the EVD was placed after the procedure and antithrombotic loading dose, one on the same day and the other on postoperative day 2. There was no intraoperative rupture of aneurysm or hemorrhage related to ventriculostomy placement or systemic hemorrhagic events. Successful stent deployment was achieved in all cases without any significant technical difficulties.

There were two episodes of stent thrombosis. The first event was an asymptomatic non-occlusive stent thrombosis which developed during stent assisted coiling procedure in a 38-year-old woman (table 1, figure 3) with right paraophthalmic blister ruptured aneurysm (presenting $\mathrm{H} \& \mathrm{H}$ grade I and Fisher grade 3 ). In this case, early stent thrombosis occurred after multiple attempts were made to place the microcatheter into the aneurysm for suitable placement of coil. At that time it was decided to abort further attempts to catheterize the aneurysm and the microcatheter was withdrawn from the parent artery. Since the aneurysm was unsecured and the stent was non-occlusive with good antegrade flow, the operator decided to observe for $45 \mathrm{~min}$ to see the progression of stent thrombosis instead of administering a thrombolytic drug. The patient was given additional 
Figure 1 (A) A 49-year-old women with multiple cerebrovascular risk factors presented with subarachnoid hemorrhage Hunt and Hess grade IV and Fisher grade 3 due to a ruptured basilar artery $(B A)$ bifurcation aneurysm. (B) Patient underwent stent assisted repair of the aneurysm in the acute phase.
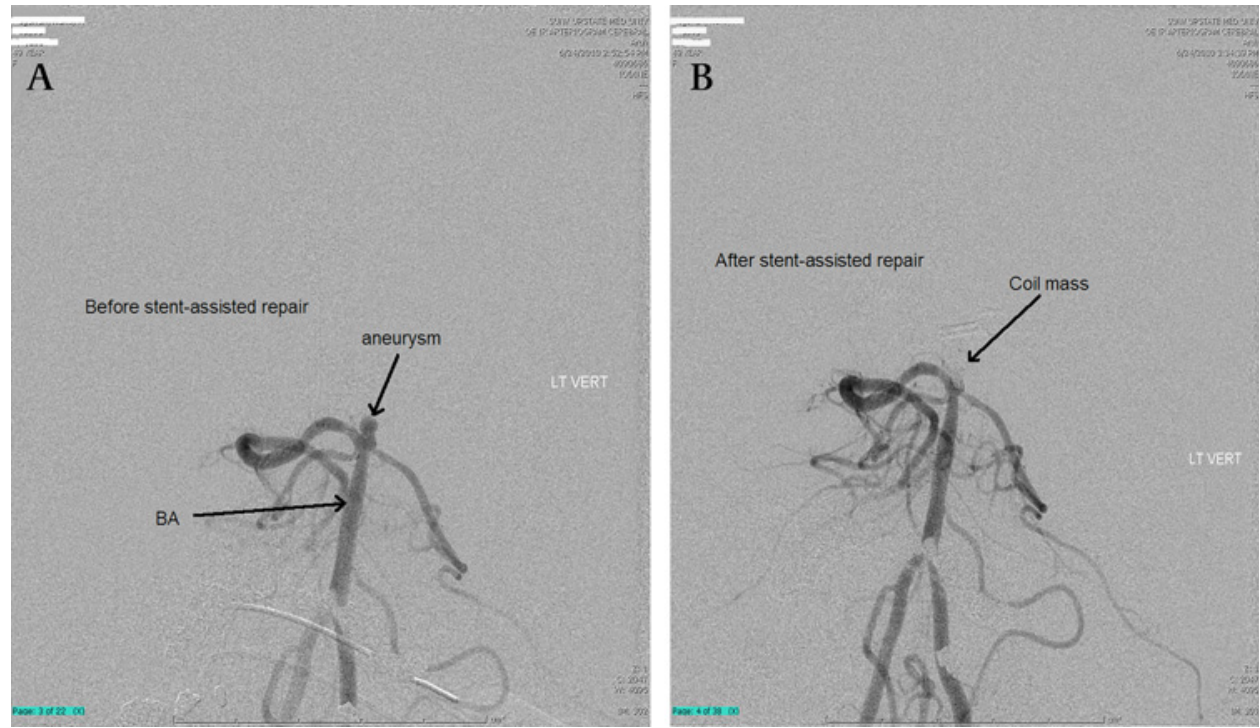

intravenous fluid and blood pressure was kept at the higher limit of normal. Within 20 min after withdrawal of the microcatheter, stent thrombosis began to resolve spontaneously and showed complete resolution in $45 \mathrm{~min}$. The procedure was rescheduled in 6 days when successful placement of coil was achieved without any recurrent thrombosis. The patient was discharged home after 21 days with a GOS score of 5 . The second event was observed on postoperative day 2 in a 46-year-old woman with $\mathrm{H} \& \mathrm{H}$ grade III and Fisher grade 3 who underwent stent assisted coiling of a ruptured basilar artery bifurcation aneurysm. Emergent intra-arterial administration of glycoprotein IIbIIIa receptor antagonist resulted in complete resolution of clot and symptoms. There was no mortality in our series. Good outcome was observed in $82 \%$ of patients (GOS score of 5 in 17 and GOS 4 in one) and poor outcome in 18\% of patients (GOS 3 in four).

\section{DISCUSSION}

Stent assisted coiling of ruptured wide necked intracranial aneurysm patients has been included in the series of stent assisted coiling of intracranial aneurysms ${ }^{11} 12$ and the results have been conflicting. In a recent study of 40 patients with 41 acute ruptured aneurysms treated with 41 Neuroform stents, an intraoperative intravenous dose of glycoprotein IIbIIIa receptor antagonist (eptifibatide) was given intravenously during the procedure instead of oral antiplatelets prior to stent placement. ${ }^{13}$ However, a postoperative loading dose of clopidogrel and aspirin was provided. Intraoperative rupture of aneurysm was reported in 3/41 aneurysms while non-aneurysmal intracranial hemorrhage was observed in 2/40 cases. An intraoperative radiographic thromboembolic event was observed in four cases, three of which resolved after administration of eptifibatide. Ischemic stroke was observed in 5/40 cases, one immediate and four in a delayed fashioned. In another study, ${ }^{14} 61$ patients with acutely ruptured intracranial aneurysm were treated with stent assisted coiling. Most patients received intraprocedure acetylsalicylic acid. Some received heparin before stent deployment and some received heparin after stent deployment. Most received both aspirin and clopidogrel after the procedure. Technical success was observed in $72 \%$. Intraoperative rupture of aneurysm was observed in 4/61 cases. Intraoperative thromboembolic events occurred in 9/61 cases. Mortality was observed in 20\%. Good outcome was observed (GOS 5 and 4) in $69 \%$ of cases.

In comparing the results of our study with the most recent studies $^{13}{ }^{14}$ (table 2), reporting only ruptured aneurysms, we observed no intraoperative rupture or postoperative hemorrhages in our series. In addition, compared with our series, the thromboembolic events, including stroke, were also higher in previous series, ${ }^{13}{ }^{14}$ including a study $^{13}$ that utilized
Figure 2 (A) A 42-year-old women presented with a subarachnoid hemorrhage Hunt and Hess grade I and Fisher grade 1 due to a ruptured basilar artery bifurcation complex aneurysm. (B) Patient underwent stent assisted repair in the acute phase with obliteration of the aneurysm.
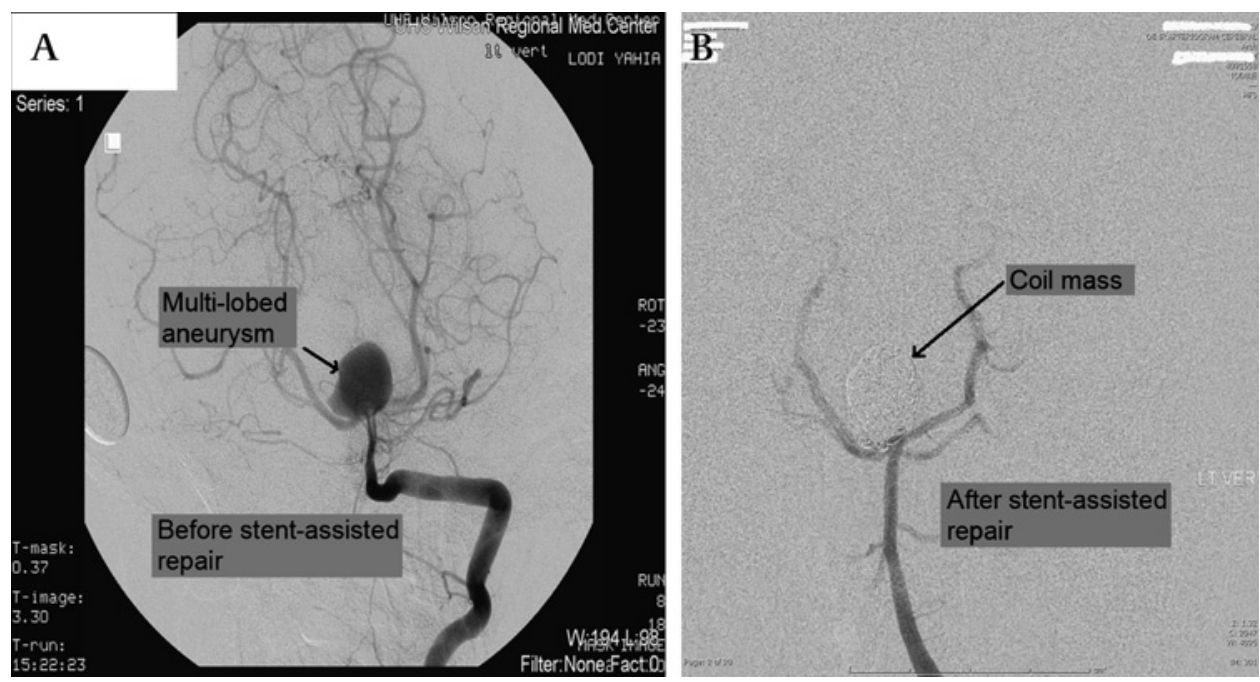
Table 1 Clinical characteristics and outcome of patients who underwent stent assisted repair of ruptured wide necked intracranial aneurysms

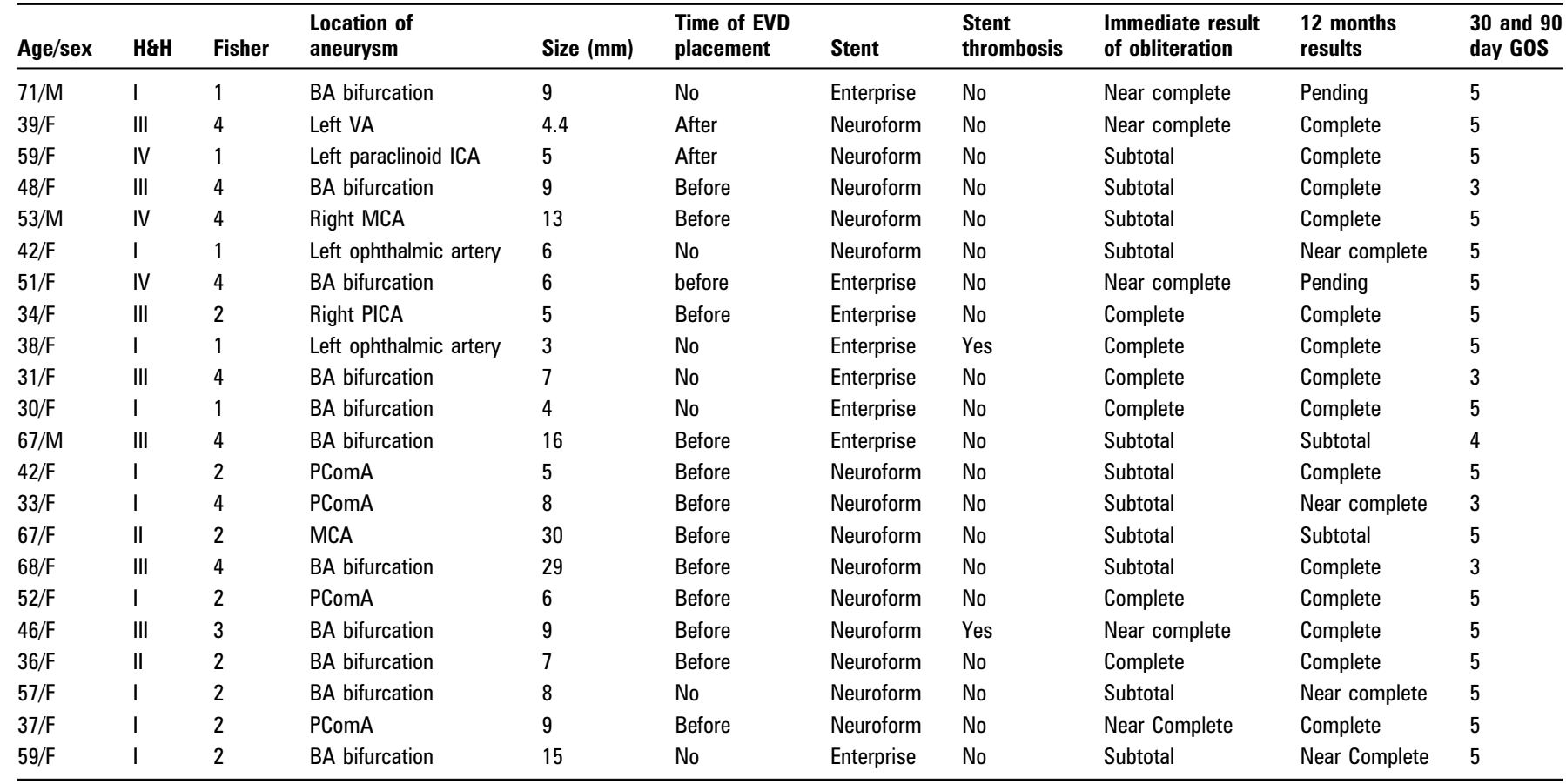

After, after endovascular procedure; Before, before endovascular procedure; BA, basilar artery; EVD, extraventricular drainage; GOS, Glasgow Outcome Scale (GOS 5, independent with no symptoms; GOS 1, dead); H\&H, Hunt and Hess grade; ICA, internal carotid artery; MCA, middle cerebral artery; PComA, posterior communication artery; PICA, posterior inferior cerebellar artery; VA, vertebral artery.
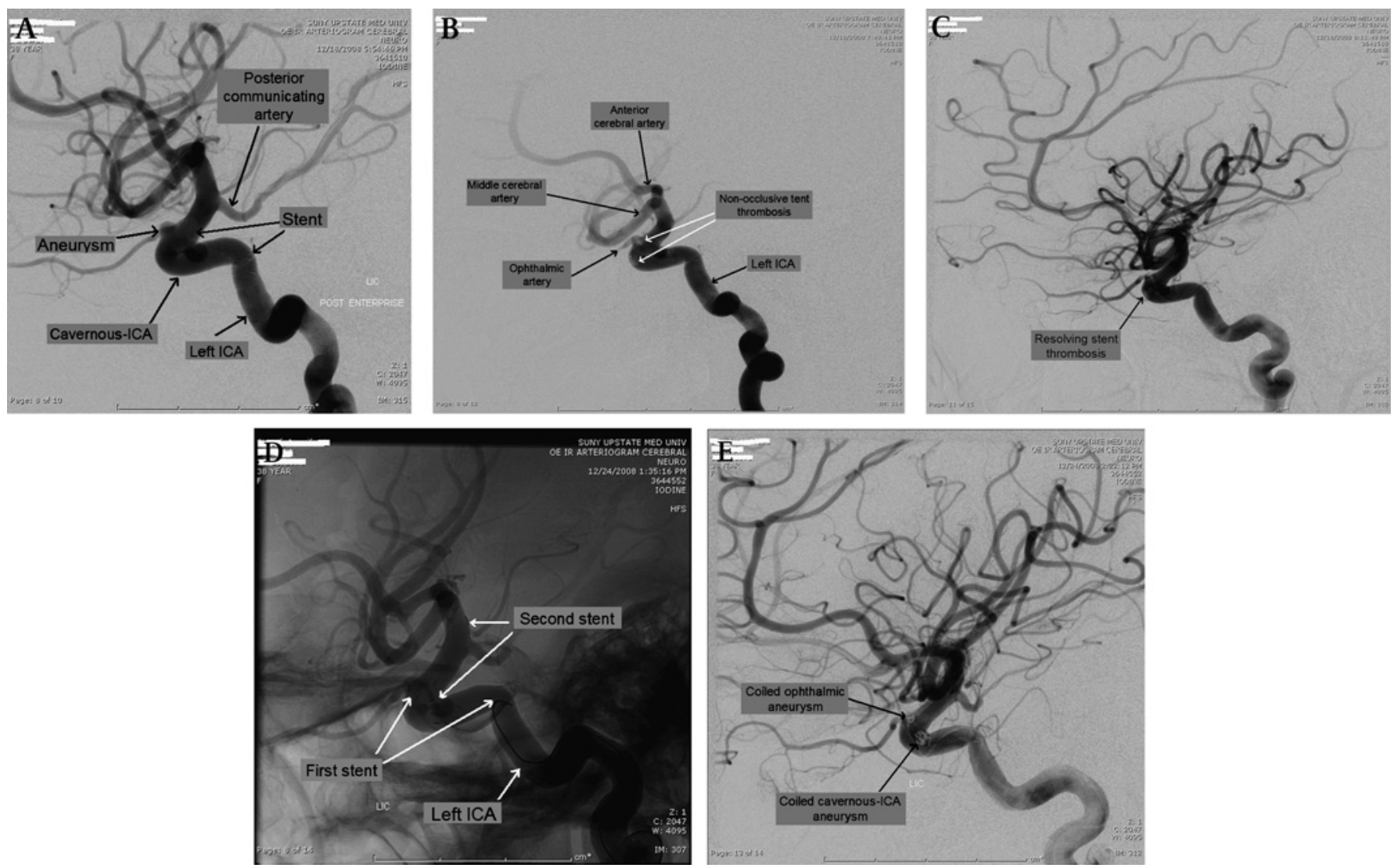

Figure 3 (A) A 38-year-old women presented with subarachnoid hemorrhage Hunt and Hess grade I and Fisher grade 1 due to a ruptured left ophthalmic internal carotid artery (ICA) aneurysm and planned to undergo stent assisted repair. A second aneurysm at the cavernous ICA was also discovered. (B) Later view angiogram of the left ICA demonstrated asymptomatic non-occlusive stent thrombosis in the ophthalmic and cavernous portions of the left ICA. (C) Lateral view angiogram of the left ICA demonstrates progressive resolution of stent thrombosis in the ophthalmic and cavernous ICA. (D) Patient underwent repeat procedure with placement of a second stent and successful coiling of the aneurysm. (E) Lateral view angiogram of the left ICA demonstrated successful coiling of the aneurysms. 


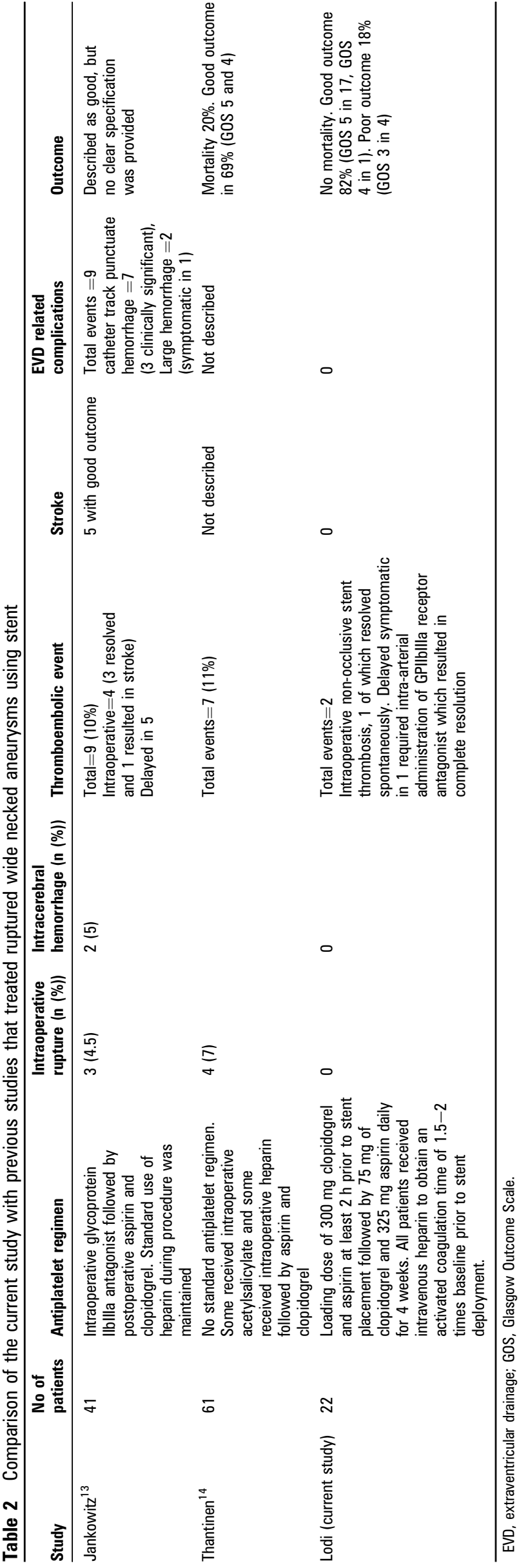

glycoprotein IIbIIIa receptor antagonist prior to stent deployment. These observations may be due to the differences in the pharmacological properties of antiplatelet agents used during stent assisted coiling of ruptured aneurysm.

The suspected mechanisms of intraoperative rupture of aneurysm during coiling including factors associated with the microwire, microcatheter or coils, have been described previously. ${ }^{7}$ When a ruptured aneurysm stops bleeding, we suspect that the hemostatic process has begun successfully by activation of platelets and formation of thrombus. After a few hours, the concentration of platelet in the thrombus increases, making the thrombus rich in platelets. Based on their pharmacological properties, the use of glycoprotein IIbIIIa receptor antagonists in unsecured aneurysms may promote breakdown of dihydrogen sulfate bondage between platelets, leading to the lysis of platelet rich clot/thrombus which then increases the chance of intraoperative rupture. Since both aspirin and clopidrogel have no effect on pre-existing clot or platelet rich thrombus, theoretically they will not increase the chance of aneurysm rupture or hemorrhage. However, in the event of aneurysm rupture or hemorrhage, both aspirin and clopidogrel may increase the severity of hemorrhages. We have not compared aspirin and clopidogrel with glycoprotein IIbIIIa receptor antagonists so we are unable to determine whether the combination of aspirin and clopidogrel has any clinical advantage over glycoprotein IIbIIIa receptor antagonists or vice versa.

Our study and other recently published series ${ }^{13}{ }^{14}$ (table 2) revealed that the incidence of thromboembolism is higher in ruptured series than in unruptured series. ${ }^{7}{ }^{12}{ }^{15}$ The possible mechanism of higher rate of thromboembolism in the ruptured series, including our series, may be due to the fact that most of our patients received antiplatelet load just $2 \mathrm{~h}$ prior to the procedure and therefore therapeutic platelet inhibition might not have been achieved prior to stent placement. Based on a previous study, ${ }^{17}$ a loading dose of clopidogrel provides platelet inhibition of $55 \%$ in $1 \mathrm{~h}$ and $80 \%$ within $5 \mathrm{~h}$ of administration. Therefore, loading doses can be administered earlier prior to stent placement which may potentially reduce intraoperative thromboembolic events. Additionally, a bedside platelet aggregations assay can be performed for all patients just before stent placement to identify those patients who have poor platelet inhibition. For the prevention of postoperative thromboembolic events, a second loading dose of antiplatelet may be administered if a platelet inhibition assay performed postprocedure indicates poor platelet inhibition.

Our study has several limitations. Firstly, the small size of our series may be insufficient to capture the true incidence of bleeding complications of periprocedural regimens of dual antiplatelets and intraoperative intravenous heparin that we used in our cohort of patients treated for ruptured wide neck intracranial aneurysm. Secondly, in our series we did not use a balloon assisted technique in which some of these aneurysms could hypothetically have been repaired. Thirdly, the retrospective, single arm and open label design of our study may limit its external validity. However, what we report here is a pilot study examining mainly the safety, feasibility and outcome of the dual antiplatelet regimen that we used in our patients cohort.

In conclusion, in carefully selected cases, stent assisted coiling of ruptured wide necked intracranial aneurysm using preprocedural aspirin and clopidogrel loading is feasible and not associated with increased bleeding complications. Ventriculostomy related complications could be avoided if the ventriculostomy is performed at least $6 \mathrm{~h}$ prior to the antiplatelet loading dose. However, the thromboembolic events remain the main challenge 
in stent assisted coiling of ruptured intracranial wide necked aneurysm. Therefore, standard antiplatelet regimens should not be withheld prior to stent assisted coiling of carefully selected ruptured wide necked aneurysms. A larger prospective and blinded study looking at the same outcomes in a similar cohort is needed to replicate and confirm our results.

\section{Competing interests None.}

Ethics approval Institutional Review Board approval was obtained.

Provenance and peer review Not commissioned; externally peer reviewed.

\section{REFERENCES}

1. Fiorella D, Albuquerque $\mathrm{FC}$, Han $\mathrm{P}$, et al. Preliminary experience using the Neuroform stent for the treatment of cerebral aneurysms. Neurosurgery 2004;54:6-16.

2. Benitez RP, Silva MT, Klem J, et al. Endovascular occlusion of wide-necked aneurysms with a new intracranial microstent (Neuroform) and detachable coils. Neurosurgery 2004;54:1359-67.

3. dos Santos Souza MP, Agid R, Willinsky RA, et al. Microstent-assisted coiling for wide-necked intracranial aneurysms. Can J Neurol Sci 2005;32:71-81.

4. Lylyk P, Ferrario A, Pasbon B, et al. Buenos Aires experience with the Neuroform self-expanding stent for the treatment of intracranial aneurysms. J Neurosurg 2005; 102:235-41.

5. Fiorella D, Albuquerque FC, Deshmukh VR, et al. Usefulness of the Neuroform stent for the treatment of cerebral aneurysms: results at initial (3-6-mo) follow-up. Neurosurgery 2005;56:1191-201.

6. Biondi A, Janardhan V, Katz JM, et al. Neuroform stent-assisted coil embolization of wide-neck intracranial aneurysms: strategies in stent deployment and midterm follow-up. Neurosurgery 2007;61:460-8.
7. Yahia AM, Gordon V, Whapham J, et al. Complications of Neuroform stent in endovascular treatment of intracranial aneurysms. Neurocrit Care 2008;8:19-30.

8. Sani S, Jobe KW, Lopes DK. Treatment of wide-necked cerebral aneurysms with the Neuroform2 Treo stent. A prospective 6-month study. Neurosurg Focus 2005;18:E4.

9. Wanke I, Doerfler A, Schoch B, et al. Treatment of wide-necked intracranial aneurysms with a self-expanding stent system: initial clinical experience. AJNR Am J Neuroradiol 2003;24:1192-9.

10. Katsaridis V, Papagiannaki C, Violaris C. Embolization of acutely ruptured and unruptured wide-necked cerebral aneurysms using the neuroform2 stent without pretreatment with antiplatelets: a single center experience. AJNR Am J Neuroradiol 2006;27:1123-8.

11. Mordasini P, Walser A, Gralla J, et al. Stent placement in the endovascular treatment of intracranial aneurysms. Swiss Med Wkly 2008;138:646-54.

12. Mocco J, Hanel RA, Sharma J, et al. Use of a vascular reconstruction device to salvage acute ischemic occlusions refractory to traditional endovascular recanalization methods. J Neurosurg 2010;112:557-62.

13. Jankowitz B, Thomas AJ, Vora N, et al. Risk of hemorrhage in combined Neuroform stenting and coil embolization of acutely ruptured intracranial aneurysms. Interv Neuroradiol 2008;14:385-96.

14. Tahtinen OI, Vanninen RL, Manninen HI, et al. Wide-necked intracranial aneurysms: treatment with stent-assisted coil embolization during acute $(<72$ hours $)$ subarachnoid hemorrhage-experience in 61 consecutive patients. Radiology 2009;253:199-208.

15. Yahia AM, Latorre J, Gordon V, et al. Thromboembolic events associated with neuroform stent in endovascular treatment of intracranial aneurysms. J Neuroimaging 2010;20:113-17.

16. Yahia AM, Gordon V, Whapham J, et al. Sapphire platinum detachable coil experience in a tertiary-care facility. Neurocrit Care 2007;7:128-35.

17. Moshfegh K, Redondo M, Julmy F, et al. Antiplatelet effects of clopidogrel compared with aspirin after myocardial infarction: enhanced inhibitory effects of combination therapy. J Am Coll Cardiol 2000;36:699-705.

\section{Correction}

K A Blackham, P M Meyers, T A Abruzzo, et al. Endovascular therapy of acute ischemic stroke: report of the Standards of Practice Committee of the Society of NeuroInterventional Surgery. J NeuroIntervent Surg 2012;4:287-93.

The author name F C Alberquerque should have been spelt FC Albuquerque.

Muhammad Shazam Hussain was missing from the author list. The list now reads: K A Blackham, P M Meyers, T A Abruzzo, F C Albuquerque, D Fiorella, J Fraser, D Frei, C D Gandhi, D V Heck, J A Hirsch, D P Hsu, M Shazam Hussain, M Jayaraman, S Narayanan, C Prestigiacomo, J L Sunshine, on behalf of the Society for NeuroInterventional Surgery.

J Neurolntervent Surg 2012:4:286. doi:10.1136/neurintsurg-2011-010243corr2 